\title{
Extraction of Spear Grass (Imperata Cylindrica) As Pro-Oxidant In Polymer Blends
}

\author{
M.A. Nuradibah ${ }^{1,}{ }^{*}$, N. A. Abdul Halim ${ }^{1}$, K.F. Kasim ${ }^{1}$, S.T. Sam ${ }^{1}$, H.I. Zulhaimi ${ }^{1}$ and Muhammad Nur Aiman Uda ${ }^{1}$ \\ ${ }^{1}$ School of Bioprocess Engineering, Kompleks Pusat Pengajian Jejawi 3, Universiti Malaysia Perlis, 02600 Arau, Perlis.
}

\begin{abstract}
Packaging material such as plastic bags is one of the main factors that contribute to the environmental pollution due to slow degradation. The usage of metal oxide as pro-oxidant has been proven to accelerate the degradation of these materials, but the excessive usage of this pro-oxidant will be harmful to the human body. Therefore, in this research, spear grass is investigated to be used as natural based prooxidant that can increase the degradation rate of the polymers. In terms of that, spear grass is extracted by using pressurized hot water extraction (PHWE) to obtain the metal element such as zinc (Zn) and ferum $(\mathrm{Fe})$. PHWE is using water as a solvent which is highly favourable due to non-toxicity and non-flammable characteristics that make it easy to handle. Box-Behnken design is used to optimize the temperature, extraction time, and sample-to-solvent ratio to get the maximum amount of $\mathrm{Zn}$ and $\mathrm{Fe}$ concentration from the extracted spear grass. As a conclusion, the leaf of spear grass contributed the highest amount of $\mathrm{Zn}$ and $\mathrm{Fe}$ concentration. The highest amount of $\mathrm{Zn}$ and Fe concentration is achieved at $150{ }^{\circ} \mathrm{C}, 20$ minutes, and 3 $\mathrm{g}$ of sample to $45 \mathrm{ml}$ of water.
\end{abstract}

\section{Introduction}

From the last decades, the search for solutions to minimize environmental problem due to polymeric materials such as polyethylene has increase necessity when it disposed in an appropriate environment [1]. Polyethylene represents $64 \%$ of plastic materials produced as packaging and bottles, which usually discarded after only brief use due to easily contaminated, recycling these materials is not effortless and recovery cost is higher than cost producing. As the effects, several thousand tonnes of goods made from plastic materials are sent to landfill, and increasing the amount of municipal waste [2]. Due to their low degradability, generating pollution and taking space in landfills, plastics accumulate in environment.

Polyethylene is considered as an inert bulk polymer which is slowly degradable. Polyethylene in its pure form is extremely resistant to environmental degradation. Khabbaz et al. (2001) has estimated that polyethylene would degrade less than $0.5 \%$ in 100 years, and $1 \%$ if exposed to sunlight for 2 years before biodegradation [3]. Roy et al. (2007) stated that to produce degradable polyethylene is to mix it with pro-oxidant additives that can effectively improve the degradability of these materials [4]. Metallic salt is comprised in the commercial polyethylene as the most additives being used which is harmful to human body if used in excessive quantity. The usage of metal oxides as chemical based pro-oxidant such as is cobalt stearate that led to toxicity that can cause damage to major constituents of biological system.

Imperata cylindrica also known as spear grass in Nigeria, alang-alang in Asia, and cogongrass in America is a perennial rhizomatous grass which has the high up to $1.2 \mathrm{~m}$. Spear grass is the most dominant, competitive, and difficult weed to control in Asia, West Africa, and Latin America [5]. Spear grass can act as natural pro-oxidant that can increase the degradation of the polymer by reducing their molecular weight. In order to do that, spear grass need to be extracted to obtain essential ingredients that can make it act as pro-oxidant. Ferum $(\mathrm{Fe})$ and zinc $(\mathrm{Zn})$ are metal elements that an important content in spear grass that can accelerate the degradation.

In this project, spear grass as pro-oxidant will be extracted by using pressurized hot water extraction (PHWE). PHWE is feasible green solvent extraction that used water as extraction solvent as it utilized pressurized water at elevated temperature and controlled pressure conditions. Water as solvent is highly favourable because water is non-toxicity and non-flammable characteristics that make it easy to handle. In the various report, the polarity of water can be varied close to those of alcohols at certain temperature and applied pressure. Thus water can dissolve a large range of medium and categorized as low polarity analytes [6-7].

\section{Materials and Procedures}

\subsection{Materials}

The spear grass was collected from Kuala Perlis. The spear grass was grounded to fine powder. Distilled water was used as solvent for extraction process.

*Corresponding author: nuradibah@unimap.edu.my 


\subsection{Procedures}

\subsubsection{Preparation of sample}

The plant which is spear grass (Imperata cylindrica) was collected from Kuala Perlis, Perlis. The spear grass was separated to different parts which were leaf, root, and straw. It was washed thoroughly under running tap water to get rid dirt, dust, and soil. Then, the plant was undergoing drying process by using oven at $50{ }^{\circ} \mathrm{C}$ for 24 hours. After that, the spear grass was crushed by using grinder and sieved to $63 \mu \mathrm{m}$ particle sized to get powder form.

\subsubsection{Extraction of spear grass}

To identify the best extraction method, three type of extraction which is cold extraction, hot extraction, and pressurized hot water extraction (PHWE) was conducted. For cold extraction, $2 \mathrm{~g}$ of spear grass was mixed with 20 $\mathrm{ml}$ of water and leaved at room temperature for about 3 hours. For hot extraction, $2 \mathrm{~g}$ of spear grass was mixed with $20 \mathrm{ml}$ water and was stirred using hot plate stirrer for about 3 hours at $100^{\circ} \mathrm{C}$. For PHWE, $2 \mathrm{~g}$ of spear grass was mixed with $20 \mathrm{ml}$ water and the sample was extracted at $150{ }^{\circ} \mathrm{C}$ for 20 minutes. After that, the extracted sample was analyzed using atomic absorption spectroscopy (AAS) and the best extraction method was proceeding for screening process.

\subsubsection{Screening different part of spear grass}

After the extraction process, $2 \mathrm{~g}$ of different part of spear grass (leaf, root, and straw) were undergone screening process by using pressurized hot water extraction (PHWE) at constant temperature, extraction time, and sample-tosolvent ratio.

Table 1. Experimental Design for Optimization under BoxBenhken Design
After the extraction process has done, the amount of metal element contains in spear grass was determined by using Atomic Absorption Spectroscopy (AAS). The screening process was repeated for three times.

\subsubsection{Extraction of selected part using PHWE}

The selected part of spear grass with the highest amount of $\mathrm{Fe}$ and $\mathrm{Zn}$ that obtain from the screening process was extracted using pressurized hot water extractor (PHWE) at different temperature, extraction time, and sample-tosolvent ratio. The extracted spear grass was centrifuge at $4000 \mathrm{rpm}$ at $4{ }^{\circ} \mathrm{C}$ for 10 minutes to separate the residue and the liquid. After that, the sample was filtered using syringe filter $0.2 \mu \mathrm{m}$ to ensure that no residue in the sample. After the extraction process, Atomic Absorption Spectroscopy (AAS) was used to measure and analyze the concentration of $\mathrm{Zn}$ and $\mathrm{Fe}$ contains in spear grass.

\subsubsection{Determining optimum conditions by using Response Surface Methodology (RSM)}

The choice of design of experiment can have a large influence on the accuracy of the approximately and the cost of constructing the response process [8]. In this study, Response Surface Methodology (RSM) was used to determine the effect of different parameters that generate maximum response which is the amount of $\mathrm{Fe}$ and $\mathrm{Zn}$. The Box-Behnken design was used to optimize the temperature, extraction time, and solvent-to-sample ratio for extraction of selected part of spear grass. Table 1 shows experimental design for optimization under BoxBehnken design.

\begin{tabular}{ccccccc}
\hline \multirow{2}{*}{$\begin{array}{c}\text { Standard } \\
\text { run }\end{array}$} & \multicolumn{6}{c}{ Parameters } \\
\cline { 2 - 7 } & \multicolumn{2}{c}{ Temperature } & \multicolumn{2}{c}{ Extraction time } & \multicolumn{2}{c}{ Sample:solvent } \\
\cline { 2 - 7 } & Coded & $\begin{array}{c}\text { Actual } \\
\text { (celcius) }\end{array}$ & Coded & $\begin{array}{c}\text { Actual } \\
\text { (minute) }\end{array}$ & Coded & $\begin{array}{c}\text { Actual } \\
(\mathrm{g} / \mathrm{ml})\end{array}$ \\
\hline 1 & 200.00 & +1 & 30.00 & 0 & 15.00 \\
\hline & +1 & & & & & \\
2 & 0 & 150.00 & -1 & 10.00 & +1 & 20.00 \\
3 & +1 & 200.00 & 0 & 20.00 & -1 & 10.00 \\
4 & 0 & 150.00 & -1 & 10.00 & -1 & 10.00 \\
5 & 0 & 150.00 & 0 & 20.00 & 0 & 15.00 \\
6 & 0 & 150.00 & +1 & 30.00 & +1 & 20.00 \\
7 & +1 & 200.00 & -1 & 10.00 & 0 & 15.00 \\
8 & 0 & 150.00 & 0 & 20.00 & 0 & 15.00 \\
9 & 0 & 150.00 & 0 & 20.00 & 0 & 15.00 \\
10 & -1 & 100.00 & +1 & 30.00 & 0 & 15.00 \\
11 & 0 & 150.00 & +1 & 30.00 & -1 & 10.00 \\
12 & 0 & 150.00 & 0 & 20.00 & 0 & 15.00 \\
13 & 0 & 150.00 & 0 & 20.00 & 0 & 15.00 \\
14 & -1 & 100.00 & 0 & 20.00 & -1 & 10.00 \\
15 & +1 & 200.00 & 0 & 20.00 & +1 & 20.00 \\
16 & -1 & 100.00 & -1 & 10.00 & 0 & 15.00 \\
17 & -1 & 100.00 & 0 & 20.00 & +1 & 20.00 \\
\hline
\end{tabular}




\section{Results and Discussions}

\subsection{Comparison of extraction method}

Pressurized hot water extraction (PHWE), hot extraction, and cold extraction for the extraction of spear grass, are compared in terms of temperature, extraction time, and sample-to-solvents ratio. Table 2 represents the concentration of zinc $(\mathrm{Zn})$ and ferum $(\mathrm{Fe})$ of spear grass by using different extraction methods.

Based on the Table 2, extraction of spear grass using PHWE is contributed the highest concentration of $\mathrm{Zn}$ and Fe with $0.7260 \mathrm{~g} / \mathrm{mL}$ and $3.4827 \mathrm{~g} / \mathrm{mL}$ respectively. It indicated that extraction by using PHWE was more efficient compared to cold and hot extraction. One of the greatest advantages of the PHWE is rapidity. An extraction time of 10 minutes provides comparable yield to those 3 hours of cold and hot extraction. The ultimate yield of concentration of $\mathrm{Zn}$ and Fe by PHWE was the highest which means PHWE method are 2 times more efficient than cold and hot extraction. This result means a substantial saving time, energy and plant material by PHWE.

\subsection{Screening different part of spear grass}

The screening process was performed using the pressurized hot water extraction (PHWE). The constant parameters which are $150{ }^{\circ} \mathrm{C}$ of temperature, 20 minutes of extraction time, and $15 \mathrm{~mL}$ of sample-to-solvents ratio was used to investigate which part of spear grass contributed the highest amount of zinc $(\mathrm{Zn})$ and ferum (Fe) concentration. Table 3 and table 4 represent the average concentration of $\mathrm{Zn}$ and $\mathrm{Fe}$ after three set of replication.

Table 3. Concentration of zinc, $\mathrm{Zn}$

\begin{tabular}{ccccc}
\hline Sample & \multicolumn{4}{c}{ Concentration of zinc, $\mathrm{Zn}(\mathrm{g} / \mathrm{mL})$} \\
\cline { 2 - 5 } part & First set & $\begin{array}{c}\text { Second } \\
\text { set }\end{array}$ & $\begin{array}{c}\text { Third } \\
\text { set }\end{array}$ & Average \\
\hline Leaf & 0.9639 & 0.8092 & 0.5627 & 0.7786 \\
Straw & 1.0472 & 0.6370 & 0.4092 & 0.4495 \\
Root & 0.1305 & 0.1408 & 0.1606 & 0.1439 \\
\hline
\end{tabular}

Table 2. Concentration of $\mathrm{Zn}$ and Fe using different extraction methods.
Table 4. Concentration of ferum, $\mathrm{Fe}$

\begin{tabular}{lcccc}
\hline Sample & \multicolumn{4}{c}{ Concentration of ferum, Fe $(\mathrm{g} / \mathrm{mL})$} \\
\cline { 2 - 5 } part & First set & $\begin{array}{c}\text { Second } \\
\text { set }\end{array}$ & $\begin{array}{c}\text { Third } \\
\text { set }\end{array}$ & Average \\
\hline Leaf & 2.9646 & 3.8157 & 4.9571 & 3.9125 \\
Straw & 1.2746 & 2.2779 & 1.2762 & 1.6096 \\
Root & 3.8091 & 2.8215 & 3.8157 & 3.4821 \\
\hline
\end{tabular}

Based on the result represents in Table 3 and Table 4, it indicates that the leaf part from the spear grass contributed the highest amount of zinc and ferum with $0.7786 \mathrm{~g} / \mathrm{mL}$ and $3.9125 \mathrm{~g} / \mathrm{mL}$, respectively. Hence, the leaf part of spear grass was chosen to proceed for optimization of spear grass.

\subsection{Optimization of spear grass using pressurized hot water extraction (PHWE)}

\subsection{Regression analysis in Box-Behnken Design}

Response Surface Methodology (RSM) is a model which comprises of statistical and mathematical techniques to study the effect of variables and to determine the optimum conditions that generates the maximum response. In the present study, by using the Design Expert 7.1.5 software, the experimental design and the data analysis were easier to observe and interpreted. . From the screening different part of spear grass, the leaf part was chosen as a result of highest concentration of zinc $(\mathrm{Zn})$ and ferum $(\mathrm{Fe})$. A BoxBehnken Design which is one of the components of RSM was applied to analyze the interaction between three parameters with $\mathrm{Zn}$ and $\mathrm{Fe}$ content in spear grass as a response. Table 5 represents the result based on BoxBehnken design for $\mathrm{Zn}$ and $\mathrm{Fe}$ concentration.

\begin{tabular}{lccccc}
\hline \multirow{2}{*}{$\begin{array}{c}\text { Extraction } \\
\text { method }\end{array}$} & $\begin{array}{c}\text { Pemperature } \\
\left({ }^{\circ} \mathrm{C}\right)\end{array}$ & $\begin{array}{c}\text { Extraction } \\
\text { time } \\
(\mathrm{min})\end{array}$ & $\begin{array}{c}\text { Sample:solvent } \\
(\mathrm{mL})\end{array}$ & $\mathrm{Zn}$ & $\mathrm{Fe}$ \\
& & 10 & 10.00 & 0.7260 & 3.4827 \\
& 150 & $1 \mathrm{~g} / \mathrm{mL})$ & \\
\hline PHWE & 37 & 180 & 10.00 & 0.2111 & 1.2211 \\
Cold & 100 & 180 & 10.00 & 0.3423 & 0.5404 \\
Hot & & & & & \\
\hline
\end{tabular}


Table 5. Zinc, Zn concentration $(\mathrm{g} / \mathrm{ml})$

\begin{tabular}{cccccc}
\hline $\begin{array}{c}\text { Run } \\
\text { no. }\end{array}$ & \multicolumn{3}{c}{ Factor } & \multicolumn{2}{c}{ Response } \\
\cline { 2 - 6 } & $\begin{array}{c}\mathrm{A} \\
\text { Temperature } \\
(\text { Celsius })\end{array}$ & $\begin{array}{c}\mathrm{B} \\
\text { Extraction time } \\
(\text { minute) }\end{array}$ & $\begin{array}{c}\mathrm{C} \\
\text { Sample:solvent } \\
(\mathrm{mL})\end{array}$ & $\begin{array}{c}\text { Zn Concentration } \\
(\mathrm{g} / \mathrm{mL})\end{array}$ & $\begin{array}{c}\text { Fe concentration } \\
(\mathrm{g} / \mathrm{mL})\end{array}$ \\
\hline 1 & 200.00 & 30.00 & 15.00 & 1.2338 & 2.9361 \\
2 & 150.00 & 10.00 & 20.00 & 1.0158 & 1.3595 \\
3 & 200.00 & 20.00 & 10.00 & 0.9591 & 2.2742 \\
4 & 150.00 & 10.00 & 10.00 & 0.6593 & 3.1827 \\
5 & 150.00 & 20.00 & 15.00 & 1.7732 & 3.0423 \\
6 & 150.00 & 30.00 & 20.00 & 0.9401 & 2.4251 \\
7 & 200.00 & 10.00 & 15.00 & 0.4402 & 1.2554 \\
8 & 150.00 & 20.00 & 15.00 & 1.5369 & 2.9811 \\
9 & 150.00 & 20.00 & 15.00 & 1.5543 & 3.0323 \\
10 & 100.00 & 30.00 & 15.00 & 0.6552 & 1.6453 \\
11 & 150.00 & 30.00 & 10.00 & 0.8358 & 2.3407 \\
12 & 150.00 & 20.00 & 15.00 & 1.5482 & 3.0353 \\
13 & 150.00 & 20.00 & 15.00 & 1.5537 & 3.0158 \\
14 & 100.00 & 20.00 & 10.00 & 0.7426 & 2.2684 \\
15 & 200.00 & 20.00 & 20.00 & 0.7377 & 2.0684 \\
16 & 100.00 & 10.00 & 15.00 & 0.6772 & 1.7396 \\
17 & 100.00 & 20.00 & 20.00 & 0.6708 & 1.2367 \\
\hline
\end{tabular}

\subsection{Regression analysis of zinc (Zn) concentration}

A regression analysis was performed to fit the empirical model based on the second order equation. The regression equation model is given as equation 1 .

$$
\begin{gathered}
\mathrm{Y}=1.59+0.078 \mathrm{~A}+0.011 \mathrm{~B}+0.021 \mathrm{C}-0.037 \mathrm{AC} \\
-0.063 \mathrm{BC}-0.46 \mathrm{~A}^{2} \\
-0.038 \mathrm{~B}^{2}-0.035 \mathrm{C}^{2}
\end{gathered}
$$

$\mathrm{Y}$ was referred as the response of zinc ( $\mathrm{Zn}$ ) concentration $(\mathrm{g} / \mathrm{mL})$, A represent temperature, B represent extraction time, and $\mathrm{C}$ represent sample-tosolvent ratio. The variable of $\mathrm{AB}$ is indicated the interaction effect between temperature and extraction time, $\mathrm{AC}$ is indicated interaction effect between temperature and sample-to-solvent ratio, while $\mathrm{BC}$ is indicated the interaction effect between extraction time and sample-to-solvent ratio. $\mathrm{A}^{2}, \mathrm{~B}^{2}$, and $\mathrm{C}^{2}$ were quadratic effects to show the present of curvature in the model.

Table 6 illustrates the statistical data to test the fit of the model.
Table 6. Test of significance for regression square

\begin{tabular}{lc}
\hline Standard deviation & 0.16 \\
$\mathrm{R}^{2}$ & 0.9391 \\
Adjusted $\mathrm{R}^{2}$ & 0.8609 \\
Predicted $\mathrm{R}^{2}$ & 0.7385 \\
Adequate precision & 9.050 \\
\hline
\end{tabular}

For testing the goodness of fit of regression equation, the determination coefficient $\left(\mathrm{R}^{2}\right)$ was evaluated. Hence, the value of determination coefficient, $\mathrm{R}^{2}=0.9391$ showed that $93.91 \%$ of the data obtained were distributed evenly in this quadratic model. The $\mathrm{R}^{2}$ value $\geq 0.8$ was acceptable. The $\mathrm{R}^{2}$ value which more than $80 \%$ represent the good agreement between predicted data and experimental data. Adequate precision measures the signal to noise ratio. A ratio greater than 4 is desirable. Ratio of 9.050 indicates an adequate signal.

\subsection{Regression analysis of ferum concentration}

A regression analysis was performed to fit the empirical model based on the second order equation. The regression equation model is given as equation 2 . 


$$
\begin{array}{r}
\mathrm{Y}=3.02+0.21 \mathrm{~A}+0.23 \mathrm{~B}-0.37 \mathrm{C}+0.44 \mathrm{AB} \\
+0.21 \mathrm{AC}+0.48 \mathrm{BC}-0.75 \mathrm{~A}^{2} \\
-0.38 \mathrm{~B}^{2}-0.31 \mathrm{C}^{2}
\end{array}
$$

$\mathrm{Y}$ was referred as the response of ferum $(\mathrm{Fe})$ concentration $(\mathrm{g} / \mathrm{mL})$, A represent temperature, B represent extraction time, and $\mathrm{C}$ represent sample-tosolvent ratio. The variable of $\mathrm{AB}$ is indicated the interaction effect between temperature and extraction time, AC is indicated interaction effect between temperature and sample-to-solvent ratio, while $\mathrm{BC}$ is indicated the interaction effect between extraction time and sample-to-solvent ratio. $\mathrm{A}^{2}, \mathrm{~B}^{2}$, and $\mathrm{C}^{2}$ were quadratic effects to show the present of curvature in the model.

Table 7 illustrates the statistical data to test the fit of the model.

Table 7. Test of significance for regression square

\begin{tabular}{lr}
\hline Standard deviation & 0.19 \\
Mean & 2.34 \\
$\mathrm{R}^{2}$ & 0.9653 \\
Adjusted $^{2}$ & 0.9208 \\
Predicted $\mathrm{R}^{2}$ & 0.4500 \\
Adequate precision & 12.328 \\
\hline
\end{tabular}

For testing the goodness of fit of regression equation, the determination coefficient $\left(\mathrm{R}^{2}\right)$ was evaluated. Hence, the value of determination coefficient, $\mathrm{R}^{2}=0.9653$ showed that $96.53 \%$ of the data obtained were distributed evenly in this quadratic model. The $\mathrm{R}^{2}$ value $\geq 0.8$ was acceptable. The $\mathrm{R}^{2}$ value which more than $80 \%$ represent the good agreement between predicted data and experimental data. Adequate precision measures the signal to noise ratio. A ratio greater than 4 is desirable. Ratio of 12.328 of indicates an adequate signal and good agreement between the signals to the noise ratio.

\subsection{Summary}

Based on the three parameter involved in the research, there were many factors that identified as the significant factor. The concentration of zinc and ferum on PHWE was successfully demonstrated by the RSM. Figure 1 and Figure 2 represents the model analysis of $\mathrm{Zn}$ and $\mathrm{Fe}$ concentration. The model obtained was good as the $\mathrm{R}^{2}$ value is 0.9391 for $\mathrm{Zn}$ concentration and 0.9653 for $\mathrm{Fe}$ concentration. It implies the good agreement. From the model analysis, it showed that each parameter affected the concentration of $\mathrm{Zn}$ and $\mathrm{Fe}$ concentration. Based on Figure, the red dot in the elliptical indicates the highest concentration of $\mathrm{Zn}$ concentration which is $1.55433 \mathrm{~g} / \mathrm{mL}$ and the highest concentration of $\mathrm{Fe}$ which is 3.03237 $\mathrm{g} / \mathrm{mL}$.

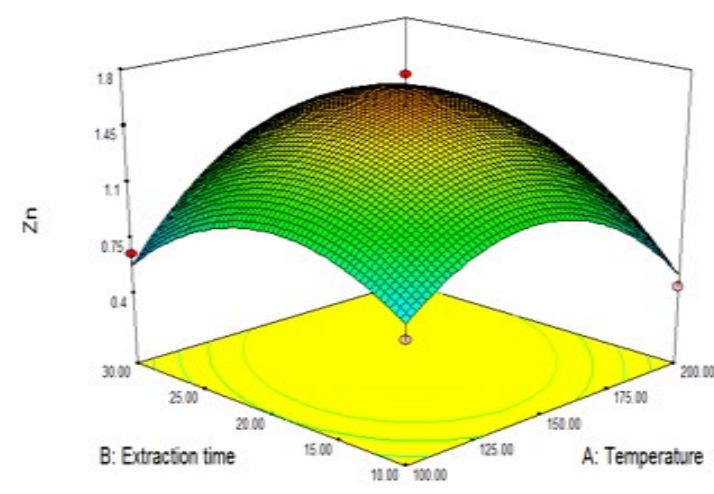

Fig. 1. Highest concentration of zinc, $\mathrm{Zn}$

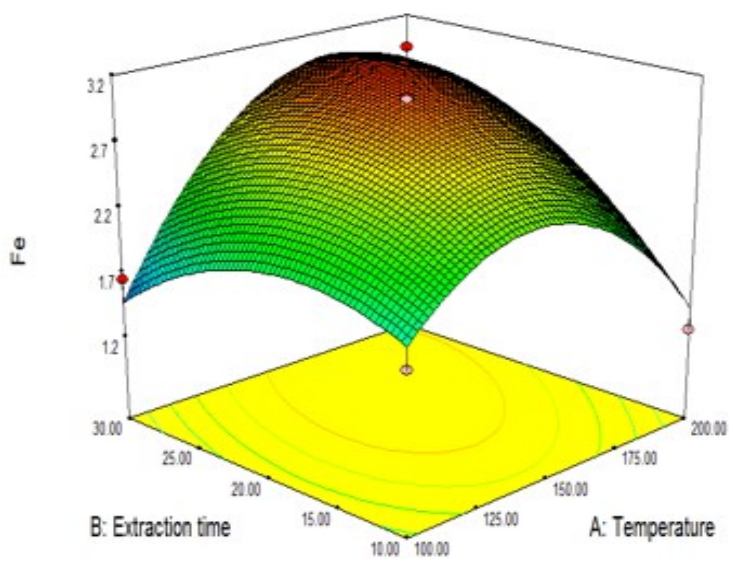

Fig. 2. Highest concentration of ferum, Fe

The sign of regression coefficients indicates that all three parameters have an effect on $\mathrm{Zn}$ and Fe concentration. The surface response curves in the both Figure show that the concentration of $\mathrm{Zn}$ and $\mathrm{Fe}$ increase with temperature, extraction time, and sample-to-solvents ratio, however after achieve the maximum level, the concentration of $\mathrm{Zn}$ and $\mathrm{Fe}$ will be decrease. At $150{ }^{\circ} \mathrm{C}$ of temperature, 20 minutes of extraction time, and $15 \mathrm{~mL}$ of sample-tosolvent ratio, the optimum conditions has achieved.

\section{Conclusion}

Spear grass sample were extracted to obtain metal elements such as zinc and ferum. These type of metal elements can be categorized as natural based pro-oxidant. Pressurized hot water extraction required a shorter time than cold and hot extraction method, provides the quality extracted spear grass. Therefore, in this research, the spear grass was extracted by using pressurized hot water extraction.

After the screening process, the leaf part from the spear grass contributed the highest amount of $\mathrm{Zn}$ and $\mathrm{Fe}$ concentration. The box-behnken design method was used to optimize the operating conditions parameters. The optimum conditions of temperature, extraction time, and 
sample-to-solvent ratio were adjusted at $150{ }^{\circ} \mathrm{C}, 20 \mathrm{~min}$, and $3 \mathrm{~g}$ of sample to $45 \mathrm{~mL}$ of water, respectively, to achieve the highest amount of $\mathrm{Zn}$ and Fe concentration.

\section{Acknowledgement}

We are grateful to Short Term Research Grant (STG) 9001-00551 from Universiti Malaysia Perlis for funding this research.

\section{References}

1. I. Kyrikou, B. Demetres, M. Hiskakis, M. E. Babou, Polym. Degrad. Stab. 96(12), 2237-2252 (2011)

2. M.J. Kirwan, J.W. Strawbridge, Food. Packag.Technol. CRC Press: New York, 174-240.

3. F. Khabbaz, A.C. Albertsson, J. Appl. Polym. Sci. 79(12), 2309-2316 (2001)

4. P.K. Roy, P. Surekha, C. Rajagopa, V. Choudhary, Express. Polym. Lett. 1(4), 208-216 (2007)

5. D.P. Garrity, M. Soekardi, M.V. Noordwijk, R. Cruz, P.S. Pathak, H.P.M. Gunasena, N.V. So, G. Huijun, N.M. Majid, Agrofor. Syst. 36, 3-29 (1997)

6. C.C. Teo, S.N. Tan, J.W.H. Yong, C.S. Hew, E.S. Ong, J. Chromatogr. A. 1217(16), 2484-2494 (2010)

7. C. Deng, N. Yao, A. Wang, X. Zhang, Anal. Chim. Acta. 536(1-2), 237-244 (2005)

8. D.B. Hibbert, J. Chromatogr. B. 910, 2-13 (2012) 